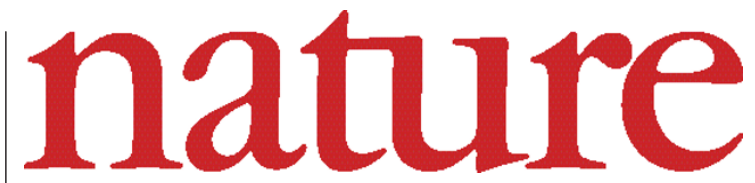

28 November 2002 Volume 420 Issue no 6914

\title{
Fighting malaria from the front
}

Too much of malaria research is piecemeal, and the organizations that are supposed to support it are insufficiently effective. Better focusing could yield more funds.

"F osters a 'not my problem' culture;" "Repeatedly fails to deliver on targets;" "Blames others;" "Makes excuses." These unfavourable indicators typical of modern performance management ring too true in relation to the organizations that are fighting malaria. Although much has been achieved, international and national bodies, not least the African governments concerned, need to be held more accountable for their actions - or inaction. More rigorous and frequent evaluation and oversight at all levels is needed.

Resources are scarce, making it doubly essential to define priorities and funding in the war against this devastating disease. The troops are willing, as testified by the gathering last week in Arusha, Tanzania, of some 950 of them (see page 351), including over 400 Africans. There were regiments representing the myriad skills required to secure a victory: basic researchers who are developing tomorrow's weapons, and helping today's to be used more effectively; special forces and infantry, charged with the groundwork in control and the clinic; and strategists and paymasters, who ultimately control many of the purse and political strings.

Yet good leadership is too often lacking. A recent independent review slammed the international community's flagship control effort, Roll Back Malaria (RBM), which was launched in 1998 by the World Health Organization (WHO) with help from country donors, the World Bank and several arms of the United Nations. RBM helped to bring malaria from the political wilderness to the international spotlight, but has failed to deliver adequate progress in controlling the disease (see Nature 419, 422; 2002).
Responsibility for RBM is being transferred from the bureaucratic WHO to an independent steering group. Officials from RBM, the World Bank and others privately blame the lack of progress on each other. The new full-time executive director of RBM should be an exceptional individual capable of calming tensions, focusing the job and getting things done. The fact that widespread scepticism about RBM's effectiveness was not officially acknowledged sooner raises concerns about the degree of oversight in international health.

A brighter picture has emerged from the first five-year review of the Multilateral Initiative on Malaria (MIM), an international consortium of research agencies and funders that aims to beef up malaria research and cooperation in Africa. The MIM has notched up some successes, including nurturing several emerging pan-African research networks. But the review also recommends "strongly" that the MIM focus more on defining clearer overall objectives and target 'big picture' business plans, which may be better able to attract significant funding.

What applies to the MIM also applies to the malaria research community in general. Investigator-driven research is important, but the scarcity of funds means that it risks being piecemeal. Scientists' efforts to seek more funds by collaborating to create larger, well-defined projects with clear milestones and goals should be encouraged. Research administrators also need to be imaginative in creating flexible funding arrangements that go beyond traditional institutional boundaries. The palpable buzz in Arusha was a good sign. As the war on malaria moves forwards, especially in Africa, where most deaths occur, the troops and their generals must embrace a more professional approach.

\section{Postdoctoral abuse (cont.)}

\section{The failure to provide appropriate career structures for young scientists persists.}

$\mathrm{n}$ these enlightened times, one might expect an investigation that revealed the miserable existence of thousands of workers, who are exploited and forced to work repeatedly on contracts for low pay with few benefits or little job security, to raise at least ripple of protest. But when a British parliamentary committee highlighted the continuing plight of postdoctoral researchers last week, and pointed out that university research is now second only to the fast-food industry in the proportion of casual labour it employs, a pricked conscience or two seems to have been the best that it could hope for.

The plight of the postdoc has been well documented, not least in the pages of this journal. In recent years, Nature has covered a depressing range of reports and studies from Britain as well as France, Germany, the United States and others, all saying that postdocs are undervalued and poorly paid. There have been studies, initiatives and pilot schemes aimed at improving the situation. Why, then, does so little seem to have changed?

Often compared to an oil tanker altering course because of its slow pace, change in higher education often more closely resembles the geological formation of the oil itself. With little incentive to update employment practices that discriminate against those on fixed-term contracts, there seems to be little chance of achieving the radical change in university culture demanded by British parliamentarians (seehttp://www.parliament.uk/commons/selcom/s\&thome.htm).

Yet with few guaranteed sources of even medium-term income, the universities will rightly argue that they have at least one hand tied behind their back. Those providing the funds must also shoulder more responsibility for the well-being of those who do the research. The British government's recent decision to raise postdoc salaries by

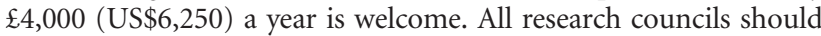
make it possible for contract researchers - many of whom have years of experience - to apply for grants in their own name.

The well-documented poor working conditions have not given rise to an international recruitment or retention crisis. A famously stoical bunch, many researchers only look as far as the next research position. What some still view as a rite of passage before a glittering career has effectively become a career in itself.

Generally, established researchers have failed to confront this issue. Too many still hold the out-of-date opinion that postdoctoral years are a 'sink or swim' exercise that "never did me any harm". On the contrary, there needs to be better management of postdoctoral careers, and better mentoring. Funding agencies should take such demonstrable commitments, or a lack of them, into account. 